\title{
Significance of combined cyclosporine-prednisolone therapy and cyclosporine blood concentration monitoring for idiopathic membranous nephropathy with steroid-resistant nephrotic syndrome: a randomized controlled multicenter trial
}

\author{
Takao Saito · Masayuki Iwano $\cdot$ Koichi Matsumoto $\cdot$ Tetsuya Mitarai Hitoshi Yokoyama Noriaki Yorioka \\ Shinichi Nishi • Ashio Yoshimura • Hiroshi Sato • Satoru Ogahara • Hideki Shuto • Yasufumi Kataoka • \\ Shiro Ueda • Akio Koyama - Shoichi Maruyama • Masaomi Nangaku • Enyu Imai - Seiichi Matsuo • \\ Yasuhiko Tomino - The Refractory Nephrotic Syndrome Study Group
}

Received: 28 February 2013/Accepted: 4 December 2013/Published online: 23 December 2013

(C) The Author(s) 2013. This article is published with open access at Springerlink.com

\begin{abstract}
Background Combined treatment with cyclosporine microemulsion preconcentrate (CyA MEPC) and steroids has been widely used for idiopathic membranous nephropathy (IMN) associated with steroid-resistant nephrotic syndrome (SRNS). Recent studies have shown that once-a-day and preprandial administration of CyA MEPC is more advantageous than the conventional twice-a-day administration in achieving the target blood CyA concentration at $2 \mathrm{~h}$ post
\end{abstract}

The other authors on behalf of the Refractory Nephrotic Syndrome Study Group are listed in the Appendix.

\section{T. Saito $(\square)$}

General Medical Research Center, Faculty of Medicine, Fukuoka

University, 7-45-1 Nanakuma, Jonan-ku, Fukuoka 814-0180,

Japan

e-mail: tsaito@fukuoka-u.ac.jp

\section{Iwano}

Division of Nephrology, Department of General Medicine,

Faculty of Medical Sciences, University of Fukui, Fukui, Japan

\section{K. Matsumoto}

The University Research Center, General Science Institute,

School of Medicine, Nihon University, Tokyo, Japan

T. Mitarai

Department of Nephrology and Blood Purification, Saitama Medical Center, Saitama Medical University, Kawagoe, Japan

H. Yokoyama

Division of Nephrology, Kanazawa Medical University School

of Medicine, Ishikawa, Japan

N. Yorioka

Hiroshima Kidney Organization, Hiroshima, Japan dose $(\mathrm{C} 2)$. We designed a randomized trial to compare these administrations.

Methods IMN patients with SRNS (age 16-75 years) were divided prospectively and randomly into 2 groups. In group $1(n=23), 2-3 \mathrm{mg} / \mathrm{kg}$ body weight (BW) CyA MEPC was given orally once a day before breakfast. In group $2(n=25), 1.5 \mathrm{mg} / \mathrm{kg} \mathrm{BW}$ CyA MEPC was given twice a day before meals. CyA + prednisolone was continued for 48 weeks.

Results Group 1 showed a significantly higher cumulative complete remission $(\mathrm{CR})$ rate $(p=0.0282)$, but not when incomplete remission 1 (ICR1; urine protein $0.3-1.0 \mathrm{~g} /$ day) was added ( $p=0.314)$. Because a C2 of $600 \mathrm{ng} / \mathrm{mL}$ was determined as the best cut-off point, groups 1 and 2 were

S. Nishi

Division of Nephrology and Kidney Center, Kobe University

Graduate School of Medicine, Kobe, Japan

A. Yoshimura

Division of Nephrology, Department of Internal Medicine,

Showa University Fujigaoka Hospital, Yokohama, Japan

H. Sato

Division of Nephrology, Tohoku University Graduate School of Medicine, Sendai, Japan

\section{S. Ogahara}

Division of Nephrology and Rheumatology, Faculty of

Medicine, Fukuoka University, Fukuoka, Japan

H. Shuto · Y. Kataoka

Department of Pharmaceutical Care and Health Sciences,

Faculty of Pharmaceutical Sciences, Fukuoka University,

Fukuoka, Japan

S. Ueda

Ueda Clinic, Chiba, Japan 
further divided into subgroups $\mathrm{A}(\mathrm{C} 2 \geq 600 \mathrm{ng} / \mathrm{mL})$ and $\mathrm{B}$ $(\mathrm{C} 2<600 \mathrm{ng} / \mathrm{mL})$. Groups $1 \mathrm{~A}$ and $2 \mathrm{~A}$ revealed significantly higher cumulative remission (CR + ICR1) $(p=0.0069)$ and $\mathrm{CR}$-alone $(p=0.0028)$ rates. On the other hand, 3 patients with high CyA levels (C2 >900 ng/ $\mathrm{mL}$ ) in Group 1A were withdrawn from the study because of complications.

Conclusion $\mathrm{CyA}+$ prednisolone treatment is effective for IMN with associated SRNS at a C2 of $\geq 600 \mathrm{ng} / \mathrm{mL}$. To achieve remission, preprandial once-a-day administration of CyA at 2-3 mg/kg BW may be the most appropriate option. However, we should adjust the dosage of CyA by therapeutic drug monitoring to avoid complications.

Keywords Cyclosporine - Idiopathic membranous nephropathy - Steroid-resistant nephrotic syndrome · Once-a-day administration - Preprandial administration . Therapeutic drug monitoring

\section{Introduction}

Idiopathic membranous nephropathy (IMN) is the most representative disease associated with steroid-resistant nephrotic syndrome (SRNS) in adults. Although the combination of steroids and immunosuppressants, e.g., cyclophosphamide (CPA) and chlorambucil, has been reported to induce and maintain remission in randomized controlled studies [1, 2], the beneficial effects remain controversial because of the harmful side-effects of the alkylating agents. Moreover, in our cohort study of 1,000 cases in Japan, combined treatment with steroids and CPA was not superior to steroid monotherapy [3]. Recently, cyclosporine (CyA), a calcineurin inhibitor, has been introduced as an effective agent for SRNS, and several randomized controlled trials (RCTs) on the combination of steroids and CyA showed significant remission rates [4-6].

\footnotetext{
A. Koyama

Department of Nephrology, Tsukuba Memorial Hospital, Ibaraki, Japan

S. Maruyama $\cdot$ S. Matsuo

Department of Nephrology, Nagoya University Graduate School of Medicine, Nagoya, Japan

M. Nangaku

Division of Nephrology and Endocrinology, University of Tokyo School of Medicine, Tokyo, Japan

E. Imai

Nakayamadera Imai Clinic, Hyogo, Japan

Y. Tomino

Division of Nephrology, Department of Internal Medicine, Juntendo University Faculty of Medicine, Tokyo, Japan
}

However, it has been recognized that clinical response does not correlate well with the administration dose. Accordingly, careful attention to the CyA concentration in blood is essential for the optimization of therapy [7]. For this reason, the blood concentration of the drug was previously monitored at the trough level before administration (C0) because the absorption of CyA is highly affected by bile acid and other factors of absorption when the original CyA formulation was used orally [8]. The introduction of CyA microemulsion preconcentrate (MEPC) minimized the influence of bile acid and stabilized the absorption profile (AP) of CyA [9]. In a transplantation study, the area under the blood concentration-time curve up to $4 \mathrm{~h}$ after administration of $\mathrm{CyA}$ (AUCO-4) was believed to accurately express $\mathrm{CyA}$ absorption and sensitively predict the effect of CyA [10]. Moreover, the CyA blood concentration at $2 \mathrm{~h}$ post dose (C2) was recommended as the best surrogate single-sample marker for routine monitoring [10].

Recent studies have shown that once-a-day administration is more advantageous than the conventional twice-aday administration, because the former provides an AP showing the peak blood concentration of CyA, which may facilitate the remission of SRNS and prevent chronic CyA nephrotoxicity $[11,12]$. In addition, preprandial administration of CyA may be favorable for achieving a stable blood concentration because $\mathrm{CyA}$ is absorbed without the influence of food ingestion [12, 13]. However, there is no evidence that such therapeutic strategies contribute to the remission of SRNS.

In this study, we designed a prospective, open-label randomized trial to compare the effect of preprandial oncea-day administration of CyA with that of conventional twice-a-day administration for IMN with associated SRNS. Blood CyA concentrations at C0 and C2 were also evaluated during treatment.

\section{Methods}

This study was registered at the University Hospital Medical Information Network-Clinical Trials Registry (UMIN-CTR) under trial identification no. UMIN C000000369 and was approved by the Clinical Study Review Board at Fukuoka University Hospital (approval no. 03-129). The study was conducted in accordance with the principles of the declaration of Helsinki. Written informed consent was obtained before patient enrollment and after a thorough explanation of the trial's objectives, duration, and structure. The availability of alternative drugs, the possibility of adverse reactions, privacy measures, and the voluntary nature of the trial, including the right to withdraw without repercussions, were all carefully explained. The institutional review boards at the 
collaborating institutions also approved the protocol when requested.

\section{Patients}

SRNS patients (age 16-75 years) with IMN diagnosed by renal biopsy were enrolled through computerized registration from kidney centers in Japan between 2004 and 2007. Membranous nephropathy secondary to systemic diseases, e.g., diabetic nephropathy and collagen diseases, were excluded at registration. Nephrotic syndrome (NS) was defined according to the standard criteria in Japan [3]-(1) urine protein (UP) excretion $>3.5 \mathrm{~g} / \mathrm{day}$; (2) serum albumin $<3.0 \mathrm{~g} / \mathrm{dL}$ or serum total protein $<6.0 \mathrm{~g} / \mathrm{dL}$; (3) presence of edema; and (4) total cholesterol $>250 \mathrm{mg} / \mathrm{dL}$. At least the first and second criteria were necessary for the diagnosis. SRNS was determined when patients did not achieve complete remission (CR) or incomplete remission (ICR) 1 (as described in 'Clinical assessment' section) after

Table 1 Inclusion and exclusion criteria

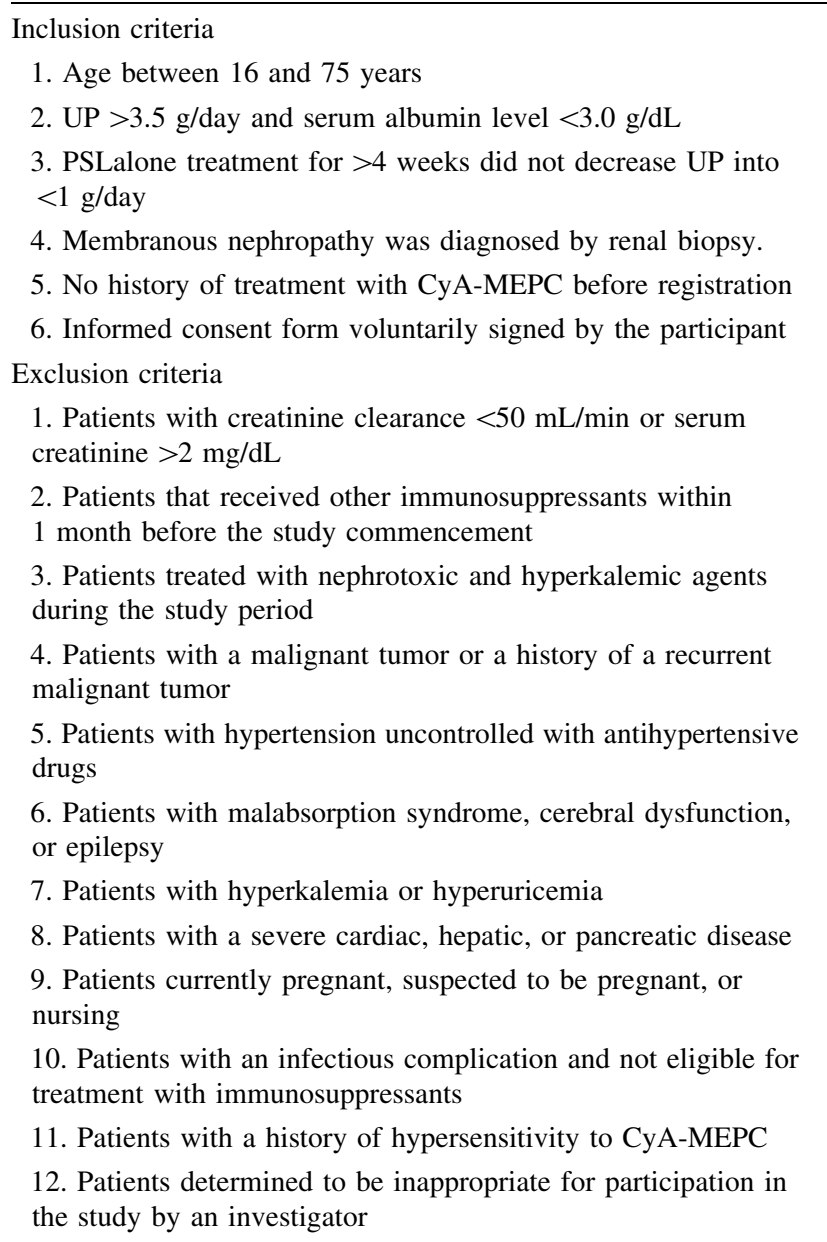

$U P$ urine protein, $P S L$ prednisolone, $C y A-M E P C$ cyclosporine microemulsion preconcentrate
4 weeks of prednisolone (PSL) therapy at 40-60 mg/day. The inclusion and exclusion criteria are listed in Table 1.

Renal histology was assessed according to the following 5 parameters-presence of global sclerosis and segmental sclerosis in glomeruli, severity of tubulointerstitial changes, occurrence of vascular lesions, and ultrastructural stage of glomerular lesions according to the criteria of Ehrenreich and Churg [14]. These changes were estimated semiquantitatively as we previously reported [3], and compared between groups.

\section{Study design}

Patients were divided prospectively and randomly into 2 groups (groups 1 and 2). Combined administration of PSL and CyA MEPC was continued for 48 weeks. PSL was initially prescribed at $40 \mathrm{mg} /$ day and tapered gradually to $<10 \mathrm{mg}$ /day by 48 weeks. In group 1, CyA MEPC was given orally once a day before breakfast at $2-3 \mathrm{mg} / \mathrm{kg}$ body weight $(\mathrm{BW})$. In group 2, CyA MEPC was given twice a day before meals at $1.5 \mathrm{mg} / \mathrm{kg} \mathrm{BW}$ each. Other agents, including antihypertensive, antidyslipidemic, and anticoagulant drugs, were allowed unless their combination with CyA was contraindicated. Biochemical data, including total protein, albumin, urea nitrogen, creatinine, and total cholesterol in serum, and 24-h UP, were assayed at 0, 4, 8, $12,24,36$, and 48 weeks.

\section{CyA treatment and monitoring}

To determine the AP of CyA in each patient, blood CyA concentrations from 0 to $4 \mathrm{~h}(\mathrm{C} 0-\mathrm{C} 4)$ were assayed within 1 month of treatment, and the AUC0-4 (ng h/mL) was calculated. The linear trapezoid formula was used with $\mathrm{C} 0$ to $\mathrm{C} 4$. Then, $\mathrm{C} 0$ and $\mathrm{C} 2$ were repeatedly assayed during the treatment period.

In group 1, CyA was started at $2 \mathrm{mg} /$ day and dose adjustments were made to achieve a $\mathrm{C} 0$ of $80-120 \mathrm{ng} / \mathrm{mL}$ and C2 of 800-1,000 ng/mL. The CyA dose was increased to a maximum of $3 \mathrm{mg} /$ day when the target $\mathrm{C} 0$ and $\mathrm{C} 2$ were not achieved. In contrast, the dose was reduced when $\mathrm{C} 0$ and $\mathrm{C} 2$ exceeded the target levels. In group 2, adjustments were also made so as not to exceed $\mathrm{C} 0$ and $\mathrm{C} 2$ by 120 and $1,000 \mathrm{mg} / \mathrm{dL}$, respectively. In the maintenance phase after remission, the dose was adjusted so as not to exceed $\mathrm{C} 0$ and $\mathrm{C} 2$ by 80 and $800 \mathrm{mg} / \mathrm{dL}$, respectively. The whole blood concentration of CyA was measured by radioimmunoassay or by the fluorescence polarization immunoassay methods of SRL Co., Japan, or the biochemical laboratory of each kidney center. The average $\mathrm{C} 0$ and $\mathrm{C} 2$ during the treatment period before remission were used for the comparison of outcomes. 


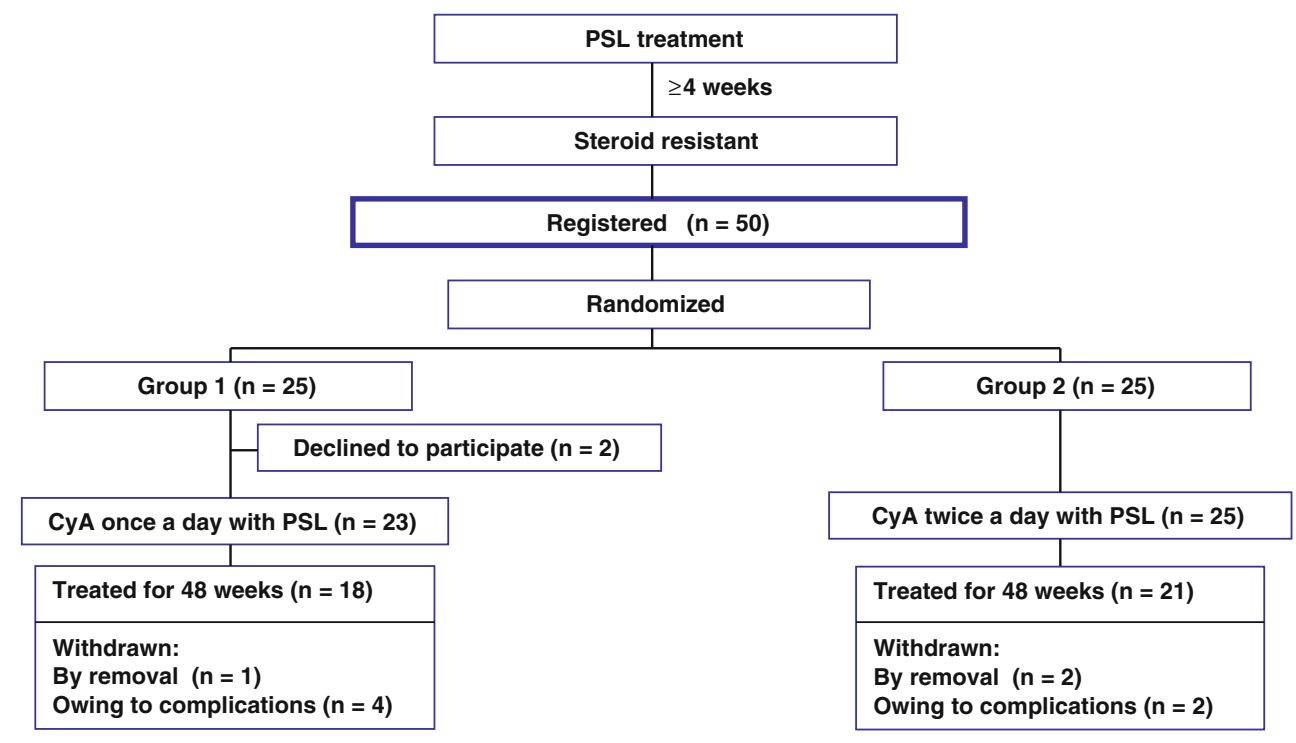

Fig. 1 Flowchart of the study design: enrollment of patients and treatment assignment

Clinical assessment

Clinical assessment of treatment outcomes was performed on the basis of changes in proteinuria and renal function, partly modified from the previous criteria in Japan [3]. Briefly, CR was defined when the UP was $<0.3 \mathrm{~g} /$ day. ICR was defined as the resolution of NS but with continuing overt proteinuria, and was divided into 2 grades-ICR1 and ICR2 for UP of $0.3-1.0$ and 1.0-3.5 g/day, respectively. No response (NR) was defined as the persistence of NS. Since patients with ICR1 showed a favorable prognosis almost equal to $\mathrm{CR}$ in a previous study [3], we considered CR + ICR1 as remission. For renal function, 3 categories were defined according to serum creatinine concentration-(1) normal renal function $<1.5 \mathrm{mg} / \mathrm{dL}$; (2) renal insufficiency $1.5-3.0 \mathrm{mg} / \mathrm{dL}$; and (3) end-stage renal disease $>3.0 \mathrm{mg} / \mathrm{dL}$.

\section{Statistical analysis}

Values were given as mean $\pm \mathrm{SE}$ or median (interquartile range). Differences in clinical characteristics between the 2 groups were evaluated with Student's $t$ test and MannWhitney $U$ test for continuous variables and Fisher's exact test for categorical variables. The incidence of remission $(\mathrm{CR}+\mathrm{ICR} 1)$ or CR was compared using Fisher's exact test. Time to remission or CR curves for the therapy groups were estimated using the Kaplan-Meier technique, and the curves were compared using the log-rank test.

The effects of blood CyA concentrations and clinical variants for the incidence of remission were examined using logistic regression analysis. The variants that affected serum CyA concentrations were examined using multiple regression analysis.
Receiver operating characteristic (ROC) curve analysis was used to test the prognostic value of serum $\mathrm{CyA}$ concentrations (average $\mathrm{C} 0$ and $\mathrm{C} 2$ ) and to determine the best cut-off for the prediction of CR.

All statistical analyses were performed using SPSS for Windows version 18.0 (SPSS Japan Inc., Tokyo, Japan).

\section{Results}

The flowchart of the study design regarding enrollment of patients and treatment assignment is shown in Fig. 1.

Patients

Fifty patients in 30 kidney centers in Japan were registered according to the inclusion criteria, from April 2004 to December 2007, and 25 patients each were randomly enrolled in the once-a-day (group 1) and twice-a-day (group 2) administration groups. However, 2 patients in group 1 declined to participate in this study before CyA treatment. Consequently, 23 and 25 patients were treated with PSL and CyA in groups 1 and 2, respectively. The baseline clinical characteristics of all patients are summarized in Table 2. There was no significant difference in each item between the 2 groups. Five parameters of renal histology estimated semiquantitatively did not show significant differences between groups (data not shown).

A previous study on IMN treated with a combination of PSL and CyA (2-3 mg/kg/day, twice-a-day) showed a $35 \%$ $\mathrm{CR}$ ratio at the 12-month course [6]. However, there were no data for once-a-day administration. Nevertheless, the sample size (groups 1 and 2: $n=23$ and $n=25$, respectively) was sufficient to detect a significant difference $(\alpha=0.05$, 
Table 2 Baseline characteristics of patients with idiopathic membranous nephropathy

\begin{tabular}{llll}
\hline Characteristic & $\begin{array}{l}\text { Group 1 } \\
(n=23)\end{array}$ & $\begin{array}{l}\text { Group 2 } \\
(n=25)\end{array}$ & $p$ \\
\hline Sex (male/female) & $16: 7$ & $17: 8$ & 0.91 \\
Age & $56(19-70)$ & $57(39-70)$ & 0.48 \\
Urine protein (g/day) & $3.5(1.8-10)$ & $3.8(1.0-6.5)$ & 0.63 \\
Serum levels & & & \\
$\quad$ Urea nitrogen (mg/dL) & $14(8-24)$ & $15(9-33)$ & 0.54 \\
Creatinine (mg/dL) & $0.8(0.5-1.2)$ & $0.8(0.6-1.6)$ & 0.84 \\
Total protein (g/dL) & $4.7(3.9-6.2)$ & $4.7(3.6-5.6)$ & 0.15 \\
Albumin (g/dL) & $2.7(2.2-3.5)$ & $2.6(1.5-3.3)$ & 0.09 \\
Total cholesterol (mg/dL) & $314(229-617)$ & $298(213-853)$ & 0.52 \\
\hline
\end{tabular}

Age and laboratory data are shown as median (interquartile range)

The $p$ values were evaluated by Fisher's exact test for sex and MannWhitney $U$ test for the others

Table 3 Withdrawn patients

\begin{tabular}{ccll}
\hline Group & $\begin{array}{l}\text { Withdrawal } \\
\text { period } \\
\text { (weeks) }\end{array}$ & Reason & $\begin{array}{l}\text { Average } \\
\text { C2 } \\
(\mathrm{ng} / \mathrm{mL})\end{array}$ \\
\hline $\begin{array}{c}\text { Group 1 } \\
(n=5)\end{array}$ & 9 & Nausea & 1042 \\
& 10 & $\begin{array}{l}\text { Uncontrolled CyA } \\
\text { level }\end{array}$ & 1200 \\
& 12 & Liver dysfunction & 750 \\
& 12 & Pneumonia & 936 \\
Group 2 & 40 & Removal & \\
$(n=4)$ & 36 & Brain tumor & 693 \\
& 10 & Noncompliance & 813 \\
& 12 & Removal & \\
& & Removal &
\end{tabular}

${ }^{a}$ May not be related to CyA administration

2 -sided) on the basis of 0.8 power according to Fisher's exact test when once-a-day administration is twice as effective (CR ratio $70 \%$ ) than twice-a-day administration. Therefore, we stopped the registration at the end of 2007.

As shown in Table 3, during the treatment, 1 patient in group 1 and 2 patients in group 2 were transferred to another hospital and could therefore not further participate in the study. Four patients in group 1 and 2 patients in group 2 were withdrawn because of complications and noncompliance. Finally, 18 and 21 patients in groups 1 and 2 completed the study for 48 weeks.

Responses in the once-a-day and twice-a-day administration groups

The response around 6 months is important to determine the initial effect of CyA treatment as shown in RCTs and

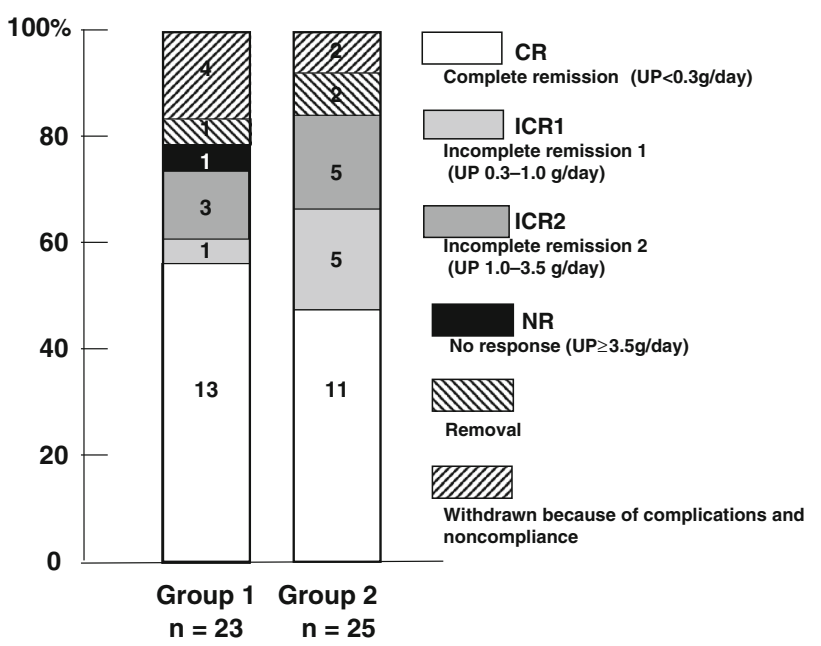

Fig. 2 Remission and withdrawal rates of groups 1 and 2 at 48 weeks. Patients were divided according to CyA administration frequency-once a day (group 1) or twice a day (group 2). In each therapeutic response, there was no significant difference

guidelines $[4,5,15-17]$. In the intention-to-treat analysis, 10 of 23 patients (43.5\%) in group 1 and 2 of 25 patients $(8.0 \%)$ in group 2 achieved CR at 24 weeks. This yielded a significant difference between groups in Fisher's exact test $(p=0.0078)$. In group 1 , two other patients achieved $\mathrm{CR}$ at 8 and 12 weeks, respectively; however, the first patient relapsed into ICR 2 by 24 weeks and the second was withdrawn thereafter because of liver dysfunction. ICR1 occurred in 1 and 10 patients in groups 1 and 2, respectively. In total, $11(47.8 \%)$ patients in group 1 and 12 $(48.0 \%)$ in group 2 achieved remission (CR + ICR1) $(p=1.000)$.

Between 24 and 48 weeks, more patients achieved CR in both groups, but a few patients with CR relapsed conversely. At 48 weeks, 13 of 23 patients (56.5\%) in group 1 and 11 of 25 patients $(44.0 \%)$ in group 2 were in CR, and 14 of $23(60.9 \%)$ in group 1 and 16 of $25(64.0 \%)$ in group 2 were in CR + ICR1 (Fig. 2). For each therapeutic response, there was no significant difference between groups. In the per-protocol analysis, similar results were statistically obtained at 24 and 48 weeks.

However, the time-to-remission curve analyzed using the Kaplan-Meier technique revealed a significant deference in cumulative CR rate ( $p=0.0282$; Fig. 3 a) but not in cumulative CR + ICR1 rate ( $p=0.314$, Fig. $3 b)$.

Assessment of clinical parameters

After CyA + PSL treatment, the levels of UP, serum albumin, and serum total cholesterol significantly improved in both groups; however, there were no significant differences in each parameter between the 2 groups. Serum creatinine level slightly increased in both groups but was 
Fig. 3 Probability of cumulative complete remission (CR) (a) and CR + incomplete remission 1 (ICRI) (b) for patients treated with PSL and CyA. Group 1 showed a significantly higher rate of $\mathrm{CR}$ (a) but not of CR + ICRI

(b) compared with group 2

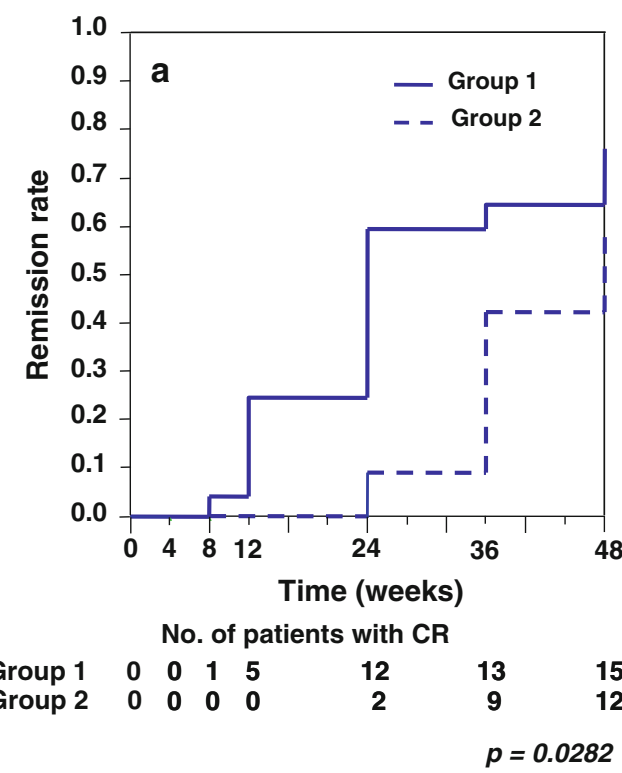

not significant. Two patients in each group exhibited a doubling of serum creatinine, around $2 \mathrm{mg} / \mathrm{dL}$, at 48 weeks, although the levels were within the reference range at the start of treatment.

At baseline, only 1 patient had mild hypertension in group $2(155 / 89 \mathrm{mmHg})$, but the blood pressure normalized later. At the final observation, another patient in group 2 showed mild hypertension $(150 / 88 \mathrm{mmHg})$. No patient had CyA-induced hypertension in either group. As the supportive therapy for MN, angiotensin II receptor blockers (4 and 2 patients in groups 1 and 2, respectively) and angiotensin-converting enzyme inhibitors (one in group 1) and a combination of both (one in each group) were administered. However, these drugs did not produce any adverse effects including hyperkalemia.

Although four patients in groups 1 and 2 showed mild hyperglycemia by steroids treatment, respectively, this did not have any serious influences on the results.

\section{Blood CyA concentrations}

The flowchart of the study design regarding assignment by blood CyA concentrations at $2 \mathrm{~h}$ post dose (C2) is shown in Fig. 4.

\section{Absorption profiles of CyA in groups 1 and 2}

There were significant differences in AUC0-4 between groups (group 1 vs group 2: $3678 \pm 181$ vs $2506 \pm 164$ $\mathrm{ng} \mathrm{h} / \mathrm{mL}, p<0.0001)$. In comparisons between AUC0-4 and $\mathrm{CyA}$ concentrations at each time point $(\mathrm{C} 0-\mathrm{C} 4), \mathrm{C} 2$ was most strongly correlated with AUC0-4 in the total patients $(r=0.032,0.609,0.780,0.654,0.579$ for $\mathrm{C} 0, \mathrm{C} 1$, $\mathrm{C} 2, \mathrm{C} 3, \mathrm{C} 4$, respectively).
Average $C O$ and $C 2$ and the cut-off level for $C R$

The average $\mathrm{C} 0$ and $\mathrm{C} 2$ during treatment were significantly correlated with the $\mathrm{C} 0$ and $\mathrm{C} 2$ at the $\mathrm{AP}$, respectively $(\mathrm{C} 0: r=0.516, p=0.0036$; $\mathrm{C} 2: r=0.638$, $p=0.0001)$. The average $\mathrm{C} 2$ in group 1 was significantly higher than in group 2; however, the average $\mathrm{C} 0$ in group 1 was significantly lower than in group 2 . Only C2 significantly predicted $\mathrm{CR}$ in logistic regression analysis based on $\mathrm{C} 0, \mathrm{C} 2$, age and baseline laboratory factors related to renal function and NS. Moreover, a multiple regression model showed that $\mathrm{C} 2$ was not significantly related to other variants as above. ROC curves were drawn to detect the optimum cut-off level of the average $\mathrm{C} 2$ or $\mathrm{C} 0$ for $\mathrm{CR}$ (Fig. 5). Using all data of the cases treated for 48 weeks in groups 1 and $2(N=37)$, the area under ROC curves were $0.731 \pm 0.089(95 \%$ CI $0.557-0.905, p=0.022$ ) for $\mathrm{C} 2$ and $0.373 \pm 0.109$ (95\% CI 0.156-0.587, not significant) for C0. From these results, the optimum cut-off point for $\mathrm{C} 2$ was determined to be $615 \mathrm{ng} / \mathrm{mL}$ (sensitivity $75.0 \%$, specificity $76.9 \%$ ); however, C0 was inappropriate to predict remission. Using the data of group 2 alone $(N=19)$, similar results were obtained. Namely, the AUCs were $0.802 \pm 0.101(95 \%$ CI $0.604-1.000, p=0.025)$ for $\mathrm{C} 2$ and $0.444 \pm 0.158$ (95\% CI $0.135-0.754$, not significant) for $\mathrm{C} 0$, and the cut-off point for $\mathrm{C} 2$ was determined to be $598 \mathrm{ng} / \mathrm{mL}$ (sensitivity $66.7 \%$, specificity $100 \%)$. When the data of $\mathrm{C} 2$ were limited to the cases $<340 \mathrm{mg} / \mathrm{dL}$ of total cholesterol $(N=25)$, the AUCs were greater $(0.868 \pm 0.072,95 \%$ CI $0.712-1.000$, $p=0.003$ ) and the cut-off point $598 \mathrm{ng} / \mathrm{mL}$ was more accurately provided (sensitivity $81.3 \%$, specificity $88.9 \%)$. 


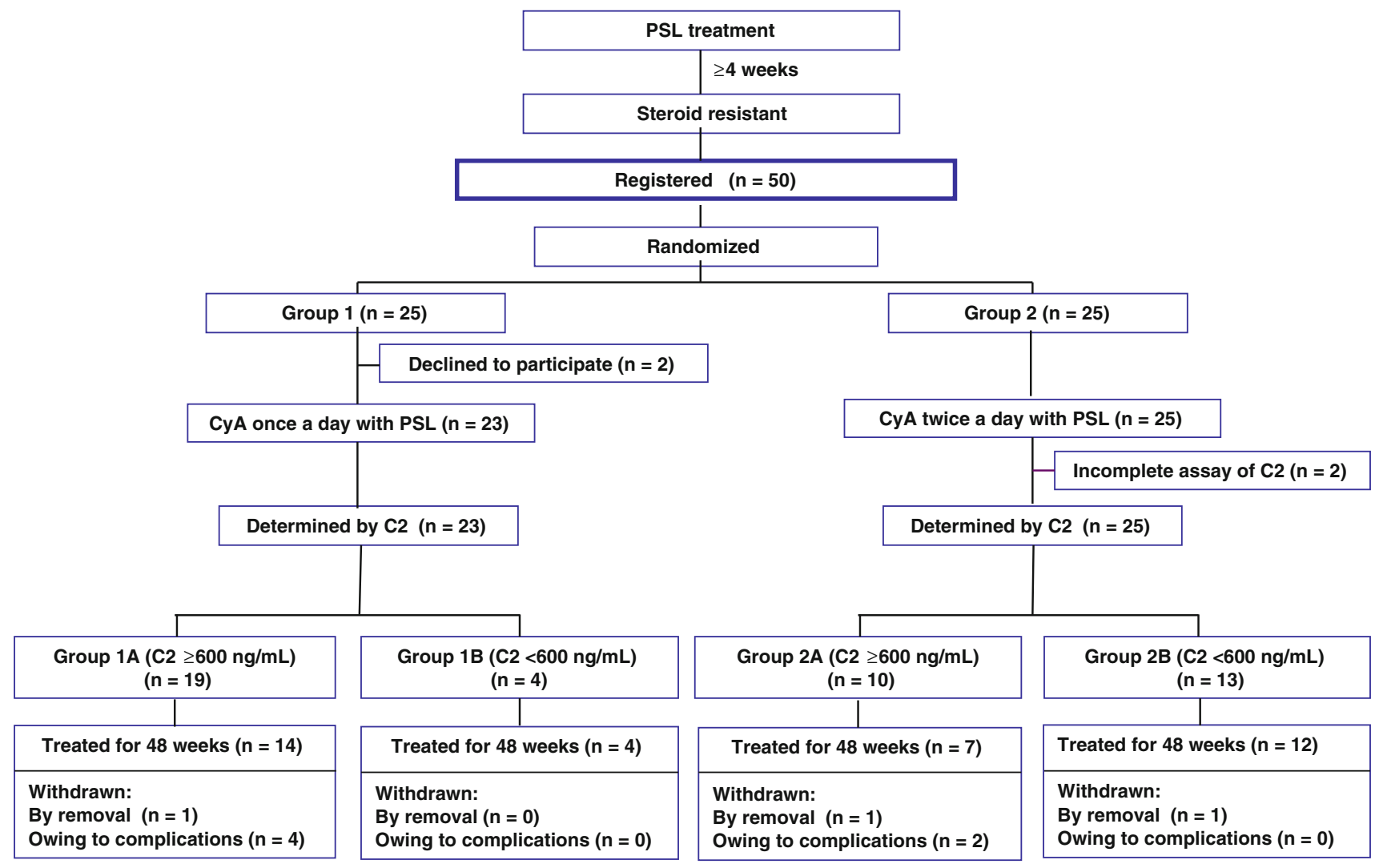

Fig. 4 Flowchart of the study design: assignment by CyA blood concentrations at $2 \mathrm{~h}$ post dose (C2)

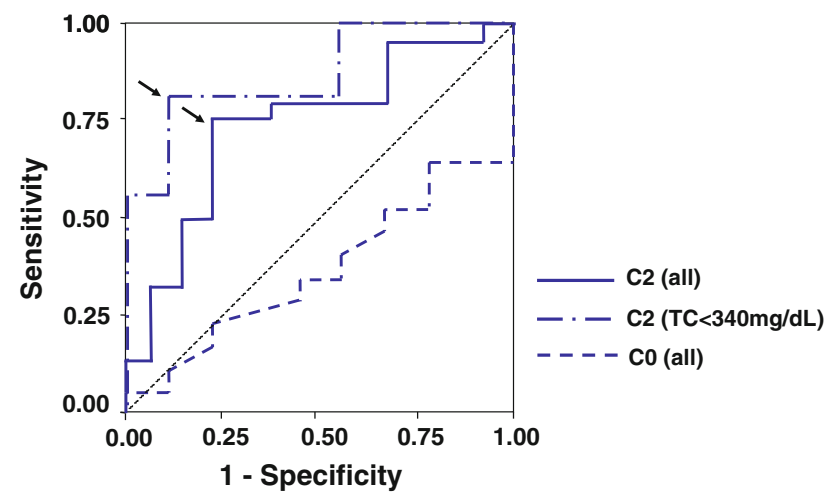

Fig. 5 Receiver operator characteristic (ROC) curves for serum CyA concentration. The optimal cut-off level of $\mathrm{C} 2$ for $\mathrm{CR}$ was determined to be $615 \mathrm{ng} / \mathrm{mL}$ (sensitivity $75.6 \%$, specificity $76.9 \%$ ) and $598 \mathrm{ng} /$ $\mathrm{mL}$ (sensitivity $81.3 \%$, specificity $88.9 \%$ ) (arrows), using the ROC curve drawn from the average C2 of all cases and the cases $<340 \mathrm{mg} /$ $\mathrm{dL}$ of total cholesterol treated for 48 weeks in groups 1 and 2, respectively

Relationship between blood CyA concentration and treatment responses

Patients in groups 1 and 2 were further divided into subgroups A $(\mathrm{C} 2 \geq 600 \mathrm{ng} / \mathrm{mL})$ and $\mathrm{B} \quad(\mathrm{C} 2<600 \mathrm{ng} / \mathrm{mL})$ because the ROC showed that the optimal cut-off point of
$\mathrm{C} 2$ was approximately $600 \mathrm{ng} / \mathrm{mL}$. The number of patients in groups $1 \mathrm{~A}, 1 \mathrm{~B}, 2 \mathrm{~A}$, and $2 \mathrm{~B}$ was $19,4,10$, and 13, respectively (Fig. 6). Most of the patients in groups $1 \mathrm{~A}$ and $2 \mathrm{~A}$ achieved CR. Among these 4 groups, groups $1 \mathrm{~A}$ and $2 \mathrm{~A}$ showed significantly higher cumulative $\mathrm{CR}$ ratios than group 2B for 48 weeks; group 1B was excluded because of the statistically insufficient number of patients (Fig. 7). Meanwhile, there was no significant difference between groups $1 \mathrm{~A}$ and $2 \mathrm{~A}$. Groups $1 \mathrm{~A}$ and $2 \mathrm{~A}$, consisting of all patients with $\mathrm{C} 2 \geq 600 \mathrm{ng} / \mathrm{mL}$, also showed a significantly higher cumulative ratio of not only CR $(p=0.0028$, Fig. 8a) but also CR + ICRI ( $p=0.0069$, Fig. $8 b)$ than groups $1 \mathrm{~B}$ and $2 \mathrm{~B}(\mathrm{C} 2<600 \mathrm{ng} / \mathrm{mL})$.

Four patients in group $1 \mathrm{~A}$ were withdrawn from the study because of complications that may be related to CyA administration (Table 3). In 3 of these 4 patients, C2 was $>900 \mathrm{ng} / \mathrm{mL}$, although there was no significant difference in $\mathrm{C} 2$ between these 4 patients and the other 21 patients in group $1 \mathrm{~A}$.

\section{Discussion}

The combined administration of CyA with steroids has been reported to be useful for the treatment of IMN with 


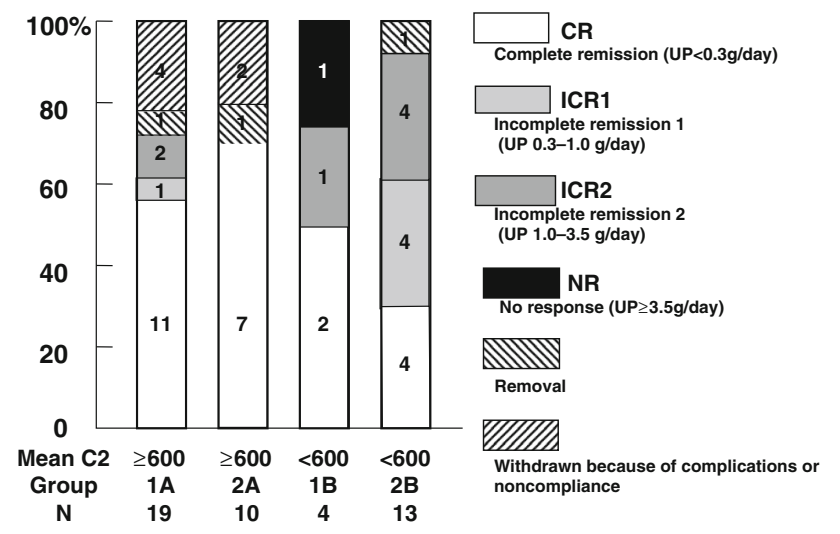

Fig. 6 Remission and withdrawal rates of groups 1A, 1B, 2A, and 2B at 48 weeks. Patients were divided into groups 1 and 2 according to administration frequency and then subdivided into subgroups $\mathrm{A}$ $(\mathrm{C} 2 \geq 600 \mathrm{ng} / \mathrm{mL})$ and $\mathrm{B}(\mathrm{C} 2<600 \mathrm{ng} / \mathrm{mL})$. There was a significant difference in CR between groups A and B ( $p=0.018$, per-protocol analysis)

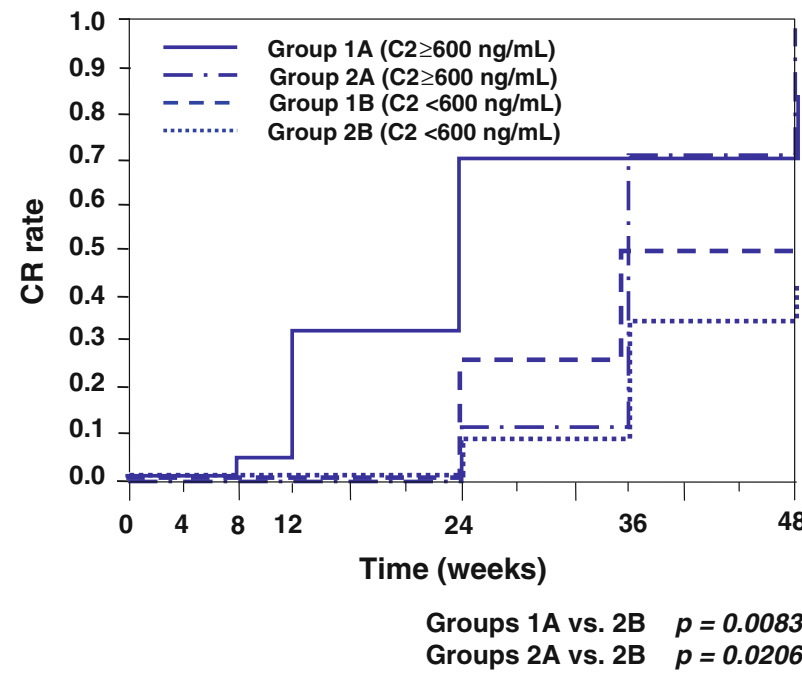

Fig. 7 Probability of cumulative CR for patients treated with PSL and CyA. Groups $1 \mathrm{~A}$ and $2 \mathrm{~A}$ showed significantly higher remissions compared with group $2 \mathrm{~B}$

associated SRNS [5, 6, 18-20]. However, only a few randomized controlled trials have succeeded in clarifying this benefit $[5,6]$. In the current randomized trial, we attempted to develop a more efficient strategy for CyA treatment by preprandial once-a-day administration. The effect of this method was significant for cumulative CR rate during 48 weeks using the Kaplan-Meier technique when compared with twice-a-day administration, but not for CR incidences at 48 weeks in the Fisher's exact test. The discrepancy of the results might be influenced by the relapsing cases because these were included in cumulative CR cases in the Kaplan-Meier technique. On the other hand, it was possible that scattered distribution of blood CyA concentrations in both groups might obscure the effect, although $\mathrm{C} 2$ in group 1 was significantly higher than group 2.

ROC curve analysis was performed to assess the predictive value of blood CyA concentration for the outcome of NS. In comparison with $\mathrm{C} 0$, only $\mathrm{C} 2$ was available for predicting CR (Fig. 5). Interestingly, the predictive value of $\mathrm{C} 2$ was more enhanced when the hypercholesterolemic cases were excluded (Fig. 5). This study may demonstrate for the first time that hyperlipidemia in NS prevents CyA treatment, although the affinity of CyA to lipoproteins has been studied in transplantation [21, 22].

The optimal cut-off points for $\mathrm{C} 2$ were calculated as 615 and $598 \mathrm{ng} / \mathrm{mL}$ in all patients and in group 2, respectively. As these results suggest that CyA might be effective for IMN when $\mathrm{C} 2$ is approximately $>600 \mathrm{ng} / \mathrm{mL}$, we divided each group into subgroups A $(\mathrm{C} 2 \geq 600 \mathrm{ng} / \mathrm{mL})$ and $\mathrm{B}$ $(\mathrm{C} 2<600 \mathrm{ng} / \mathrm{mL})$.

Among these 4 subgroups, groups $1 \mathrm{~A}$ and $2 \mathrm{~A}$ showed significantly higher cumulative CR and CR + ICRI rates. Accordingly, regardless of whether the administration is once or twice a day, CyA blood concentration is a highly sensitive marker for the remission of NS. However, once-aday administration seems to be more favorable because most of group 1 patients showed higher $\mathrm{C} 2$ concentrations. On the other hand, 3 patients in group 1A withdrawn from the study owing to complications showed an average $\mathrm{C} 2$ of $>900 \mathrm{mg} / \mathrm{dL}$, although there was no significant difference in $\mathrm{C} 2$ between the withdrawn patients and the remaining 21 patients in group 1A. Therefore, we think that the optimal strategy of CyA treatment is to maintain $\mathrm{C} 2$ between 600 and $900 \mathrm{ng} / \mathrm{mL}$ by preprandial once-a-day administration.

CyA is known to have a narrow therapeutic range of blood concentration. However, there is no study showing the relationship between drug monitoring and long-term outcomes in IMN, and $\mathrm{C} 0$ has been used as a standard parameter to determine the optimal dose of CyA without any evidence. Recently, transplantation studies [10, 23, 24] have shown that the AP of CyA-MEPC is stable and C2 is more reliable for 1-spot monitoring than $\mathrm{C} 0$ in correlation with AUC0-4. From this viewpoint, Levy et al. [28], according to the international consensus, suggested $1,400-1,600 \mathrm{ng} / \mathrm{mL}$ as the effective $\mathrm{C} 2$ in the early phase of renal transplantation. However, some authors have reported $[26,27]$ that the optimal $\mathrm{C} 2$ for Asian recipients is approximately $1,000 \mathrm{ng} / \mathrm{mL}$. In NS, to achieve such an effective level of $\mathrm{C} 2$, a few studies have confirmed that preprandial and/or once-a-day administration was superior to the conventional twice-a-day administration [11-13].

To date, it has been assumed that the immunosuppressive effect of CyA results from the inhibition of the nuclear factor of activated T-cell signaling [28]. However, the remission of NS related to the CyA blood concentration could not be completely explained by the 
Fig. 8 Probability of cumulative CR (a) and CR + ICRI (b) for patients treated with PSL and CyA. Group A $(1 \mathrm{~A}+2 \mathrm{~A})$ showed a significantly higher remission rate compared with group $\mathrm{B}$ $(1 \mathrm{~B}+2 \mathrm{~B})$ in both analyses
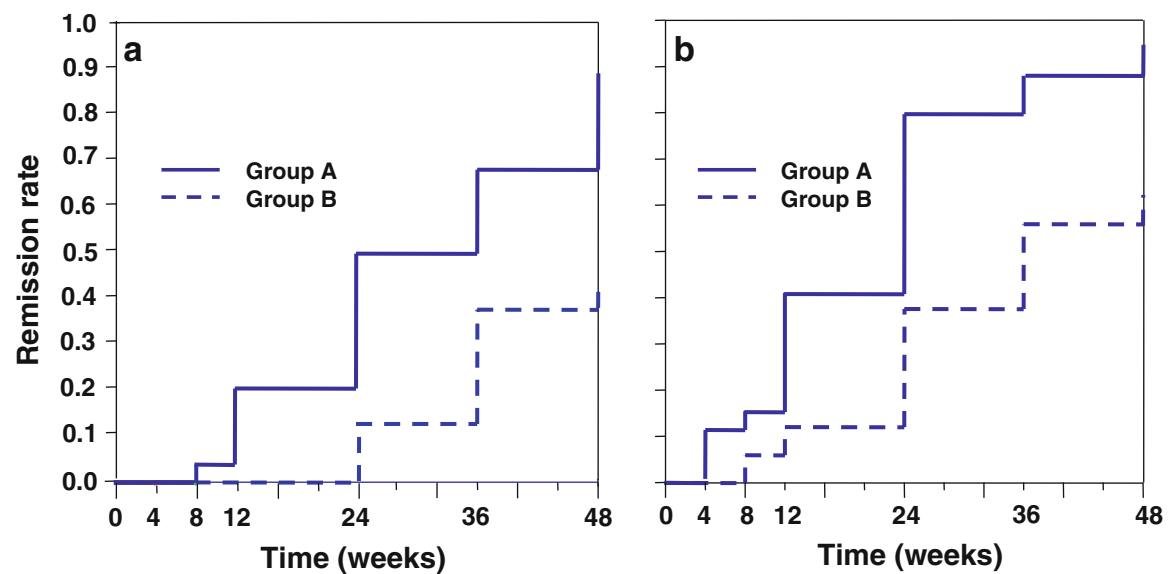

No. of patients with CR

$\begin{array}{lllll}\text { Group A } & 0 & 0 & 1 & 5\end{array}$ Group B $\quad 0 \quad 0 \quad 00$

12
2

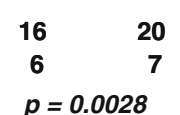

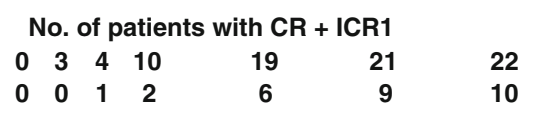

$p=0.0069$ immunosuppressive mechanism. Faul et al. [29] demonstrated that CyA blocks the calcineurin-mediated dephosphorylation of synaptopodin in podocytes, thereby preserving the phosphorylation-dependent synaptopodin14-3-3beta interaction. As a result, this direct effect of CyA on podocytes may contribute to the prompt reduction of UP, and prove the significance of CyA blood concentration monitoring on the therapeutic effect for NS. As it has been reported that steroids also directly preserve the function of podocytes [30, 31], the interaction between PSL and CyA in podocytes may play a pivotal role in the induction of remission in NS, when these agents are combined.

In the KDIGO (Kidney Disease: Improving Global Outcomes) clinical and practice guideline published in 2012 [15], the initial use of CPA with steroids was preferably recommended on the basis of evidence which was accumulated from many RCTs for over several decades. As mentioned above, however, the combined use of CyA with steroids has been recognized worldwide and was recently recommended by the Cyclosporin in Idiopathic Nephrotic Syndrome working group [16]. Moreover, the guidelines for the treatment of nephrotic syndrome in Japan [17] recommend combination treatment with steroids and CyA as the first choice for IMN because of at least 2 reasons. One is, as mentioned above, that our cohort study of 1,000 cases did not show the superiority of steroids + CPA over steroid monotherapy [3]; the other reason is that the risks of CPA use, e.g., neoplasia, agranulocytosis, and viral hepatitis, seem to be more fatal than those of CyA use, e.g., nephrotoxicity and hypertension. The current study shows that improved administration and drug monitoring are useful for increasing the benefits and decreasing the risks of CyA treatment, and may support the recommendations in the Japanese guidelines [17].
In our study, blood CyA concentration was measured by radioimmunoassay or monoclonal fluorescence polarization immunoassay. These methods are known to show 10-20\% higher levels of CyA than high-performance liquid chromatography (HPLC) as the gold standard [7] because nonspecific metabolites influence the assays [32]. On the other hand, affinity column-mediated immunoassay (ACMIA) was recognized to be comparable to HPLC [3234] and has been widely used. Accordingly, our data should be corrected to lower values if the CyA concentration is measured by a new method such as ACMIA.

In conclusion, CyA combined with PSL is effective for the treatment of IMN associated with NS when the average $\mathrm{C} 2$ is $>600 \mathrm{ng} / \mathrm{mL}$. To achieve this concentration and induce remission, preprandial once-a-day administration of CyA at $2-3 \mathrm{mg} / \mathrm{kg}$ with PSL may be the most appropriate option. However, high blood CyA concentrations >900 ng/ $\mathrm{mL}$ may frequently cause adverse effects and prevent the administration continuing. To avoid this, we should adjust the dosage of CyA by therapeutic drug monitoring.

Acknowledgments The authors greatly acknowledge the help and assistance of many colleagues in the centers and affiliated hospitals participating in this trial. We also thank Dr. M. Watanabe and Ms. M. Ueno for supporting the registration system arranging the data. This study was supported by a Grant for Progressive Renal Disease Research Projects from the Ministry of Health, Labor and Welfare, Japan, and by a Grant from the Japan Kidney Foundation.

Conflict of interest $\mathrm{T}$ Saito, $\mathrm{H}$ Yokoyama and $\mathrm{S}$ Nishi have received lecture's fees from Novartis Co. Y Kataoka and Y Tomino have received research funds from Novartis Co. Other authors have declared that no conflict of interest exists.

Open Access This article is distributed under the terms of the Creative Commons Attribution License which permits any use, distribution, and reproduction in any medium, provided the original author(s) and the source are credited. 


\section{Appendix}

The following members organized the trial:

Organizer: Takao Saito.

Protocol Committee: Hiroshi Sato, Shinichi Nishi, Tetsuya Mitarai, Koichi Matsumoto, Ashio Yoshimura, Hitoshi Yokoyama, Masayuki Iwano, Noriaki Yorioka, and Takao Saito.

Assessment Committee: Yasuhiko Tomino, Akio Koyama, and Shiro Ueda.

Statistics Committee: Yasufumi Kataoka, Hideki Shuto, and Satoru Ogahara.

Advisory Committee: Seiichi Matsuo and Enyu Imai, Masaomi Nangaku, and Shoichi Maruyama.

The following investigators participated in the trial:

Asahikawa Red Cross Hospital: Toshiya Ishiguro; Tohoku University: Hiroshi Sato; Fukushima Medical University: Masaaki Nagamichi; Saitama Medical University: Tetsuya Mitarai, Osamu Matsumura and Masaru Yoshikawa; Nihon University: Koichi Matsumoto and Takayuki Fujita; Showa University Fujigaoka Hospital: Ashio Yoshimura; Juntendo University: Yasuhiko Tomino and Yukihiko Takeda; The Jikei University: Yoichi Miyazaki; The Jikei University Kashiwa Hospital: Makoto Ogura and Akihiko Hamaguchi; Tokyo Women's Medical University: Minako Koike; Tokyo Women's Medical University Medical Center East: Masami Yoneda; Toho University: Sonoo Mizuiri; Teikyo University: Shunya Uchida; Hamamatsu University School of Medicine: Taro Misaki, Takehiko Miyaji, and Hideo Yasuda; Fujita Health University: Satoshi Sugiyama; Yokkaichi Municipal Hospital: Isao Ito; Mie University: Shinsuke Nomura; Osaka University: Enyu Imai; Nara Medical University: Hideo Shiiki and Masayuki Iwano; Kitano Hospital: Eri Muso and Toshiyuki Komiya; Niigata University: Shinichi Nishi; Kanazawa University: Hitoshi Yokoyama, Kiyoki Kitagawa and Takashi Wada; Kouseiren Takaoka Hospital: Miho Shimizu; Okayama University: Yohei Maeshima; Hiroshima University: Noriaki Yorioka and Takao Masaki; Kawasaki Medical School: Takehiko Tokura; Fukuoka University: Takao Saito and Satoru Ogahara; Miyazaki University: Seiichiro Hara; Kurume University: Keisuke Kono; Kyushu University: Kazuhiko Tsuruya.

\section{References}

1. Ponticelli C, Altieri P, Scolari F, Passerini P, Roccatello D, Cesana $\mathrm{B}$, et al. A randomized study comparing methylprednisolone plus chlorambucil versus methylprednisolone plus cyclophosphamide in idiopathic membranous nephropathy. J Am Soc Nephrol. 1998;9:444-50.

2. Jha V, Ganguli A, Saha TK, Kohli HS, Sud K, Gupta KL, et al. A randomized, controlled trial of steroids and cyclophosphamide in adults with nephrotic syndrome caused by idiopathic membranous nephropathy. J Am Soc Nephrol. 2007;18:1899-904.

3. Shiiki H, Saito T, Nishitani Y, Mitarai T, Yorioka N, Yoshimura A, et al. Prognosis and risk factors for idiopathic membranous nephropathy with nephrotic syndrome in Japan. Kidney Int. 2004;65:1400-7.

4. Cattran DC, Appel GB, Hebert LA, Hunsicker LG, Pohl MA, Hoy WE, et al. A randomized trial of cyclosporine in patients with steroid-resistant focal segmental glomerulosclerosis. Kidney Int. 1999;56:2220-6.

5. Cattran DC, Appel GB, Hebert LA, Hunsicker LG, Pohl MA, Hoy WE, et al. Cyclosporine in patients with steroid-resistant membranous nephropathy: a randomized trial. Kidney Int. 2001;59:1484-90.

6. Alexopoulos E, Papagianni A, Tsamelashvili M, Leontsini M, Memmos D. Induction and long-term treatment with cyclosporine in membranous nephropathy with the nephrotic syndrome. Nephrol Dial Transplant. 2006;21:3127-32.

7. Anonymous. Clinical issues in cyclosporine monitoring: report of the task force on cyclosporine monitoring. Clin Chem.;1987 33:1269-88.

8. Lindholm A, Henricsson S, Dahlqvist R. The effect of food and bile acid administration on the relative bioavailability of cyclosporin. Br J Clin Pharmacol. 1990;29:541-8.

9. Noble S, Markham A. Cyclosporin. A review of the pharmacokinetic properties, clinical efficacy and tolerability of a microemulsion-based formulation (Neoral). Drugs. 1995;50:924-41.

10. Nashan B, Cole E, Levy G, Thervet E. Clinical validation studies of Neoral C2 monitoring: a review. Transplantation. 2002;73:S3-11.

11. Tanaka H, Nakahata T, Ito E. Single-dose daily administration of cyclosporin A for relapsing nephrotic syndrome. Pediatr Nephrol. 2004;19:1055-8.

12. Takeda A, Horike K, Onoda H, Ohtsuka Y, Yoshida A, Uchida K, et al. Benefits of cyclosporine absorption profiling in nephrotic syndrome: preprandial once-daily administration of cyclosporine microemulsion improves slow absorption and can standardize the absorption profile. Nephrology. 2007;12:197-204.

13. Shirai S, Yasuda T, Tsuchida H, Kuboshima S, Konno Y, Shima $\mathrm{Y}$, et al. Preprandial microemulsion cyclosporine administration is effective for patients with refractory nephrotic syndrome. Clin Exp Nephrol. 2009;13:123-9.

14. Ehrenreich T, Churg J. Pathology of membranous nephropathy. In: Sommers SC, editor. The pathology annual no. 3. New York: Appleton-Century-Crofts; 1968. p. 145-86.

15. Cattran DC, Feehally J, Cook HT, Fervenza FC, Floege J, Gipson DS, et al. KDIGO clinical practice guideline for glomerulonephritis. Kidney Int Suppl. 2012;2:S139-274.

16. Cattran DC, Alexopoulos E, Heering P, Hoyer PF, Johnston A, Meyrier A, et al. Cyclosporin in idiopathic glomerular disease associated with the nephrotic syndrome: workshop recommendations. Kidney Int. 2007;72:1429-47.

17. Matsuo S, Imai E, Saito T, Taguchi T, Yokoyama H, Narita I. Guidelines for the treatment of nephrotic syndrome. Nihon Jinzo Gakkai Shi. 2011;53:78-122.

18. Rostoker G, Belghiti D, BenMaadi A, Rémy P, Lang P, Weil B, et al. Long-term cyclosporin A therapy for severe idiopathic membranous nephropathy. Nephron. 1993;63:335-41.

19. Frische L, Budde K, Färber L, Charissé G, Kunz R, Gaedeke J, et al. Treatment of membranous glomerulopathy with cyclosporin A: how much patience is required? Nephrol Dial Transplant. 1999;14:1036-8.

20. Iida H, Naito T, Sakai N, Aoki S. Effect of cyclosporine therapy on idiopathic membranous nephropathy presented with refractory nephrotic syndrome. Clin Exp Nephrol. 2000;4:81-5.

21. Rifai N, Chao FF, Pham Q, Thiessen J, Soldin SJ. The role of lipoproteins in the transport and uptake of cyclosporine and 
dihydro-tacrolimus into HepG2 and JURKAT cell lines. Clin Biochem. 1996;29:149-55.

22. Sugioka N, Kokuhu T, Okamoto M, Yoshimura N, Ito Y, Shibata $\mathrm{N}$, et al. Effect of plasma lipid on pharmacokinetics of ciclosporin and its relationship with plasma prednisolone level in renal transplant patients. J Pharm Pharmacol. 2006;58:1193-200.

23. Brunet M, Campistol JM, Millán O, Vidal E, Esforzado N, Rojo I, et al. Pharmacokinetic and pharmacodynamic correlations of cyclosporine therapy in stable renal transplant patients: evaluation of long-term target C2. Int Immunopharmacol. 2003;3:987-99.

24. Einecke G, Mai I, Fritsche L, Slowinski T, Waiser J, Neumayer $\mathrm{HH}$, et al. The value of $\mathrm{C} 2$ monitoring in stable renal allograft recipients on maintenance immunosuppression. Nephrol Dial Transplant. 2004;19:215-22.

25. Levy G, Thervet E, Lake J, Uchida K. Patient management by Neoral C(2) monitoring: an international consensus statement. Transplantation. 2002;73(9 Suppl):S12-8.

26. Praditpornsilpa K, Avihingsanon Y, Nivatvong S, Kansanabuch $\mathrm{T}$, Eiam-Ong S, Tiranathanagul K, et al. Outcome of microemulsion cyclosporine $\mathrm{C} 2$ concentration monitoring in kidney transplantation. Clin Transplant. 2005;19:335-9.

27. Wang SM, Lai MK, Chueh SC, Tai HC, Chung SD. Optimal C2 concentration of cyclosporin corrected with good efficacy and safety in Asian kidney transplant recipients. Transplant Proc. 2008;40:2243-4.

28. Crabtree GR, Olson EN. NFAT signaling: choreographing the social lives of cells. Cell. 2002;109(Suppl):S67-79.
29. Faul C, Donnelly M, Merscher-Gomez S, Chang YH, Franz S, Delfgaauw $\mathrm{J}$, et al. The actin cytoskeleton of kidney podocytes is a direct target of the antiproteinuric effect of cyclosporine A. Nat Med. 2008;14:931-8.

30. Fujii Y, Khoshnoodi J, Takenaka H, Hosoyamada M, Nakajo A, Bessho F, et al. The effect of dexamethasone on defective nephrin transport caused by ER stress: a potential mechanism for the therapeutic action of glucocorticoids in the acquired glomerular diseases. Kidney Int. 2006;69:1350-9.

31. Xing CY, Saleem MA, Coward RJ, Ni L, Witherden IR, Mathieson PW. Direct effects of dexamethasone on human podocytes. Kidney Int. 2006;70:1038-45.

32. Kagawa Y, Yanagawa M, Muraki Y, Iwamoto T, Mizutani H, Sugimura $\mathrm{Y}$, et al. Comparison of cyclosporine concentrations in renal transplant recipients using ACMIA and mFPIA methods. Clin Biochem. 2004;37:1016-21.

33. Cattaneo D, Zenoni S, Murgia S, Merlini S, Baldelli S, Perico N, et al. Comparison of different cyclosporine immunoassays to monitor $\mathrm{C} 0$ and $\mathrm{C} 2$ blood levels from kidney transplant recipients: not simply overestimation. Clin Chim Acta. 2005;355: 153-64.

34. Ventura E, Bonardet A, Pageaux GP, Mourad G, Cristol JP. Calcineurin inhibitor determination in whole blood with the RXL Dimension analyzer: a useful tool for immunosuppressive drug monitoring. Transplant Proc. 2009;41:707-9. 